Marquette University

e-Publications@Marquette

Biological Sciences Faculty Research and

Publications

Biological Sciences, Department of

$2-2015$

\title{
Unique Competitive Effects of Lianas and Trees in a Tropical Forest Understory
}

\author{
Alexandra Wright \\ University of Wisconsin - Milwaukee \\ Michael F. Tobin \\ University of Wisconsin - Milwaukee \\ Scott A. Mangan \\ University of Wisconsin - Milwaukee \\ Stefan A. Schnitzer \\ Marquette University, stefan.schnitzer@marquette.edu
}

Follow this and additional works at: https://epublications.marquette.edu/bio_fac

Part of the Biology Commons

\section{Recommended Citation}

Wright, Alexandra; Tobin, Michael F.; Mangan, Scott A.; and Schnitzer, Stefan A., "Unique Competitive Effects of Lianas and Trees in a Tropical Forest Understory" (2015). Biological Sciences Faculty Research and Publications. 722.

https://epublications.marquette.edu/bio_fac/722 
Marquette University

e-Publications@Marquette

\title{
Biology Faculty Research and Publications/College of Arts and Sciences
}

This paper is NOT THE PUBLISHED VERSION; but the author's final, peer-reviewed manuscript. The published version may be accessed by following the link in the citation below.

Oecologia, Vol. 177, No. 2 (February, 2015): 561-569. Oㅣ. This article is @ Springer and permission has been granted for this version to appear in e-Publications@Marquette. Springer does not grant permission for this article to be further copied/distributed or hosted elsewhere without the express permission from Springer.

\section{Unique Competitive Effects of Lianas and Trees in a Tropical Forest Understory}

\author{
Alexandra Wright \\ School for Freshwater Sciences, University of Wisconsin-Milwaukee, Milwaukee \\ Bard College, Annandale-on-Hudson \\ Mike Tobin \\ School for Freshwater Sciences, University of Wisconsin-Milwaukee, Milwaukee \\ Department of Natural Sciences, University of Houston-Downtown, Houston \\ Scott Mangan \\ School for Freshwater Sciences, University of Wisconsin-Milwaukee, Milwaukee \\ Department of Biology, Washington University St. Louis, St. Louis \\ Stefan A. Schnitzer \\ School for Freshwater Sciences, University of Wisconsin-Milwaukee, Milwaukee \\ Smithsonian Tropical Research Institute, Panama, Republic of Panama
}




\section{Abstract}

Lianas are an important component of tropical forests, contributing up to $25 \%$ of the woody stems and $35 \%$ of woody species diversity. Lianas invest less in structural support but more in leaves compared to trees of similar biomass. These physiological and morphological differences suggest that lianas may interact with neighboring plants in ways that are different from similarly sized trees. However, the vast majority of past liana competition studies have failed to identify the unique competitive effects of lianas by controlling for the amount of biomass removed. We assessed liana competition in the forest understory over the course of 3 years by removing liana biomass and an equal amount of tree biomass in 40 plots at 10 sites in a secondary tropical moist forest in central Panama. We found that growth of understory trees and lianas, as well as planted seedlings, was limited due to competitive effects from both lianas and trees, though the competitive impacts varied by species, season, and size of neighbors. The removal of trees resulted in greater survival of planted seedlings compared to the removal of lianas, apparently related to a greater release from competition for light. In contrast, lianas had a species-specific negative effect on drought-tolerant Dipteryx oleifera seedlings during the dry season, potentially due to competition for water. We conclude that, at local scales, lianas and trees have unique and differential effects on understory dynamics, with lianas potentially competing more strongly during the dry season, and trees competing more strongly for light.

\section{Introduction}

Tropical forests account for more than $50 \%$ of all described species and play a disproportionately large role in the global carbon cycle (Wright 2005). Competition among plants in tropical forests may help maintain species diversity (Wright 2001) and regulate carbon dynamics (Phillips et al. 2002). Woody vines (lianas) are a key component of tropical forests, where they can commonly comprise $25 \%$ of the woody stem density, $35 \%$ of woody species richness, 2-4 \% of woody biomass, and 20-30\% of canopy foliage (Putz 1983; Gentry 1991; Schnitzer et al. 2012, 2014). Because lianas use the architecture of their host trees to reach the forest canopy, they can allocate more resources towards rapid stem elongation, growth, and leaf production, rather than allocate resources to a large stem diameter (Schnitzer and Bongers 2002). Consequently, lianas can rapidly colonize the forest canopy and deploy their foliage on top of their host tree, resulting in intense competitive impacts on neighbors (Schnitzer 2005; Kurzel et al. 2006; Ladwig and Meiners 2009; Schnitzer et al. 2014; Toledo-Aceves 2014).

While the liana growth form is indeed unique, we currently have little evidence of how this translates to lianaspecific impacts on neighbors. Specifically, the vast majority of previous studies have focused on the effects of liana competition using correlative data or by experimental liana removals (Pérez-Salicrup 2001; Toledo-Aceves and Swaine 2008; Schnitzer and Carson 2010; Schnitzer et al. 2014). While traditional liana removal experiments have demonstrated the strong competitive effects of lianas on tree recruitment, growth, and survival (Grauel and Putz 2004, Schnitzer and Carson 2010; Schnitzer et al. 2014), they failed to determine whether these effects could be uniquely attributed to lianas. In other words, these same effects might be expected following a biomass removal of any kind (lianas, trees, shrubs). Determining the unique competitive effects of lianas can only be addressed using a true procedural control (e.g., an equal removal of liana and non-liana biomass). Because lianas are an important component of tropical forests and appear to be increasing in abundance relative to trees in neotropical forests (Schnitzer and Bongers 2011; Schnitzer et al. 2014), determining the unique effects of lianas on tropical forests is essential to predicting future forest dynamics.

To date, only one other study has isolated the unique competitive effects of lianas in tropical forests by comparing liana removals with paired tree removals. Tobin et al. (2012) studied liana competition in central Panama and found that lianas had a significantly greater competitive effect on host canopy tree sap flow than did neighboring trees of similar biomass. Furthermore, the liana effect in this forest was stronger during the dry 
season than during the wet season (L. Alvarez-Cansino, personal communication). Collectively, these findings suggest that liana competition with canopy trees is stronger than predicted by biomass alone, and thus lianas have a uniquely strong competitive effect on canopy trees. This previous work, however, gives us little information about the effects of lianas on plants in the understory, which are essential to tropical forest regeneration.

We used a paired liana and tree removal experiment to test the hypothesis that lianas suppress tropical tree performance, at the seedling and sapling stages, more than trees of similar biomass. We established ten sites on Gigante Peninsula within the Barro Colorado Nature Monument in central Panama and tracked 1,440 planted seedlings, as well as 1,460 established stems over the course of 3 years to assess the effects of lianas and trees on plants in the understory.

\section{Materials and methods}

\section{Site description}

The Gigante Peninsula receives 2,600 $\mathrm{mm}$ annual rainfall, and has a pronounced dry season from December to April. The forest on the Gigante Peninsula is semi-deciduous and is a mix of mid-successional secondary and older forest (Windsor 1990). We established 10 sites on the central plateau of the Gigante Peninsula in an area dominated by approximately 60-year-old forest (Schnitzer and Carson 2010; Schnitzer et al. 2014). Within each site, we established four circular experimental plots ( $8 \mathrm{~m}$ diameter). We selected sites that were relatively flat and had at least two areas with a high concentration of liana stems and two areas with a similarly large number of tree saplings within a 30-40 m distance of each other (to reduce within site heterogeneity). After surveying the existing liana and tree stems (described below), we randomly assigned a control treatment and a removal treatment for each growth form category (liana or tree, hereafter referred to as plot type) at each site. To verify that plot type (high liana abundance vs. high tree abundance) did not actually reflect underlying abiotic factors (e.g., slope; Ledo and Schnitzer 2014), we directly and separately compared plot type of controls in our statistical model.

\section{Experimental biomass removals}

In March 2008, we surveyed all lianas and trees $>0.5 \mathrm{~cm}$ diameter measured $130 \mathrm{~cm}$ from the roots (methods follow Gerwing et al. 2006; Schnitzer et al. 2008) in each of the 10 sites (40 plots total). We calculated the biomass of each individual using growth-form-specific allometry equations (Brown 1997 for trees; Schnitzer et al. 2006 for lianas). All stems not marked for removal were measured, mapped, identified, and tagged with uniquely numbered permanent metal census tags. In May 2008, we removed approximately the same biomass at the liana removal plot and the tree removal plot within each site. All remaining stems in liana control and tree control plots were quantified in terms of biomass, but otherwise were left intact. Following the initial removal, we returned to the sites after 1 month and removed any re-growth that occurred on the cut stems. We also cut any further re-growth that occurred on any of the removed stems every 6 months following the initial removal, although by June 2009 the regrowth was limited (methods follow Schnitzer and Carson 2010).

\section{Growth of uncut stems (lianas and trees)}

Following the liana and tree removals, we measured the diameter growth of all uncut stems (lianas, and trees, hereafter referred to as "uncut stems") in all plots in November 2008, June 2009, August 2010, and August 2011. At each census, we added all new plants that either recruited into the lowest size class $(0.5 \mathrm{~cm}$ at breast height) or had newly rooted within the plots. Relative growth rates between census intervals were obtained by calculating biomass from allometry equations (Brown 1997; Schnitzer et al. 2006) and using these values to calculate RGR [RGR = In(final biomass) - In(initial biomass)/days between census intervals; Poorter and Lewis 1986]. 


\section{Seedling growth and survival}

To quantify the effects of liana and tree removal on regenerating seedlings, we established one $1 \times 1 \mathrm{~m}$ seedling subplot within each of the 40 larger plots. In March 2008, we collected seeds from three tree species on Gigante peninsula: Lacmellea panamensis, Apeiba membranaceae, and Dipteryx oleifera. The three species represented distinct life-history strategies: L. panamensis is a canopy tree species that has medium to large sized seeds and is moderately shade-tolerant (Myers and Kitajima 2007), A. membranacea is a pioneer species with small seeds that usually only regenerates in high light environments, such as treefall gaps (Tyree et al. 1998), and $D$. oleifera is a large emergent tree that has large seeds and is relatively drought-tolerant (Tyree 2003). We germinated the seeds in sterile soil in a shade-house and allowed them to grow for 2 months prior to transplanting them into the plots. In May 2008, we planted 14 seedlings of L. panamensis, 16 seedlings of $A$. membranacea, and 6 seedlings of $D$. oleiferainto each of the 40 subplots (1,440 total seedlings). We censused the seedling plots in November 2008, June 2009, November 2009, August 2010, January 2011, and August 2011-corresponding roughly to wet season and dry season measurements for 3 years. We derived speciesspecific allometry equations in June 2008 by destructively harvesting 15-30 individuals of each species from the shade-house and correlating leaf number, longest leaf length, stem length, and stem diameter (D. oleifera only) with dry weight measurements (Table $\underline{1}$ ).

Table 1 Species-specific allometric equations used for calculating aboveground biomass $(A G B)$ using height in $\mathrm{cm}$ $(H t)$, number of leaves (N/vS), longest leaf in $\mathrm{cm}(L / v)$, number of leaflets ( $N / f I)$, shortest leaf in $\mathrm{cm}(S / v)$, and basal diameter in $\mathrm{mm}$ (diam) of seedlings on Gigante Peninsula, Panama

\begin{tabular}{|l|l|l|}
\hline Species & Equation & $\boldsymbol{r}^{2}$ \\
\hline $\begin{array}{l}\text { A. } \\
\text { membranace }\end{array}$ & $\mathrm{AGB}=-0.04-(0.0009 \times \mathrm{Ht})+(0.004 \times \mathrm{Nlvs})+(0.02 \times \mathrm{LIV})$ & 0.7 \\
\hline D. oleifera & $\mathrm{AGB}=-1.3+(0.09 \times \mathrm{Nlvs})+(0.04 \times \mathrm{NIfI})+(0.12 \times \mathrm{Llv})+(0.04 \times \mathrm{Slv})+(0.009 \times \mathrm{Ht})+(0.3$ & 0.9 \\
& $9 \times \mathrm{diam})$ & 5 \\
\hline L. canadensis & $\mathrm{AGB}=-0.06-(0.001 \times \mathrm{Nlvs})+(0.01 \times \mathrm{Llv})+(0.003 \times \mathrm{Ht})$ & 0.7 \\
& & 3 \\
\hline
\end{tabular}

We also indicate the adjusted $r^{2}$ value (statistical robustness of the fit) for each allometric relationship

\section{Canopy openness measurement}

In November 2008 (after the removals), we measured canopy openness (as a proxy for light availability) $1 \mathrm{~m}$ above the ground in each of the seedling subplots using a concave spherical densiometer (Forestry Suppliers, Jackson MS, USA). Canopy openness estimated in this way is a course estimate of relative differences in light levels in the understory (Englund et al. 2000). We re-measured canopy openness in June 2009 and January 2012 to assess whether initial responses changed over the course of the study.

\section{Data analysis}

\section{Uncut stems}

We used a linear mixed effects model to analyze the importance of plot type (high liana abundance or high tree abundance) and treatment type (removal vs. control) on the growth rate (RGR) of all uncut stems. We included these two factors and their first order interaction as fixed effects. We included a nested random effects term to account for autocorrelation of measurements taken over time and space. Specifically, we included census interval as a random effect to account for autocorrelation of measurements taken over time. We included site nested within census interval as a random effect to account for random variation associated with the spatial separation of the 10 sites. We also included stem ID as a random effect nested within the above term to account for autocorrelation of measurements taken on the same individuals over time (random = census/site/stem ID). 
We included growth form of standing stems as a separate random effect in the statistical model as well. This allowed us to account for inherent differences in stem types that covaried with treatment groups (more lianas remaining in tree removals and more trees remaining in liana removals), and to test for underlying differences between treatments (included as a separate random term from the nested term described above).

Planted seedlings

We used a mixed effects model to analyze the fixed effects of plot type, treatment type, and their interaction on planted seedling growth (RGR). We also included species identity and season (dry vs. wet), as well as all higher order interactions with plot type and treatment type as fixed effects in this seedling analysis. To account for spatial variation associated with site (1-10) and spatial variation associated with multiple seedlings planted within one seedling subplot (and treatment applied at the plot level) we included plot as a random effect nested within site. We also included census number as a random effect to account for autocorrelation of measurements taken over time, and seedling ID to account for multiple measurements taken on the same individuals over time ( random = census/site/subplot/seedlingID).

For tree seedling survival, we conducted a generalized linear mixed effects model (GLMM) with a binomial distribution (link = logit) to assess the effects of all treatments on seedling survival. We conducted all analyses using the (g)Imer function in the Ime4 package in the R statistical platform.

\section{Canopy openness measurements}

We assessed how canopy openness directly above the plots changed in response to the different treatments using a mixed-effects ANOVA. Plot type, treatment type, and their interactions were included as fixed effects. Census interval and site number were included as random effects. We then assessed whether canopy openness had a direct effect on the growth of the remaining trees and lianas, as well as the species-specific growth and survival of the planted tree seedlings using linear and logistic (for survival) regression with census number, site number, and subplot included as random effects.

\section{Results}

\section{Growth of uncut stems}

When averaged across all remaining individuals we found that growth of uncut stems was greater in all removals $\left(F_{1,22}=8.0, P=0.009\right.$; Fig. $\left.\underline{1}\right)$ and there was not a unique effect of liana competition (no growth form by treatment interaction, $F_{1,22}=3.3, P=0.08$ ) or a significant difference between liana plots vs. tree plots $\left(F_{1,22}=0.09, P=0.77\right)$.

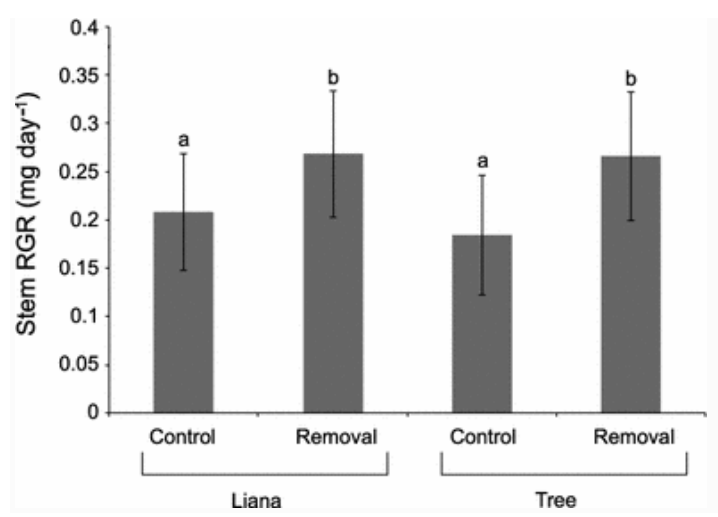

Fig. 1 Relative growth rate (RGR) of established (uncut) lianas and trees in response to either liana or tree cutting manipulations and un-manipulated control plots on Gigante Peninsula, Panama. Bars means \pm SE $(n=1,460)$, letters represent statistically different groups 


\section{Planted seedling survival}

Seedling survival was lower due to competition from both trees and lianas (Table 2 ); however, removing trees resulted in the largest increase in seedling survival (plot type $\times$ treatment interaction; Table 2; Fig. 2a). Much of the negative effects of competition (from both trees and lianas) occurred during the dry season, when survival was much higher in the removal plots (Fig. 2 b). There was also a significant interaction between species identity and season (Table 2) with drought-tolerant $D$. oleifera surviving better in the dry season than in the wet season. In contrast, $L$. panamensis showed the reverse pattern and $A$. membranacea survived at very low rates during both seasons (Fig. $\underline{3}$ ). There was also an interaction between species identity and treatment (Table $\underline{2}$ ), where all three species survived better in removals, but the response of the shade intolerant species, $A$.

membranacea, was the strongest.

Table 2 Results of ANOVA examining the effects of plot type (PT), treatment type (TT), species ID, and season on tree seedling survival on Gigante Peninsula, Panama

\begin{tabular}{|l|l|l|l|}
\hline Fixed effect & $\boldsymbol{d} \boldsymbol{f}$ & $\boldsymbol{\chi}^{\mathbf{2}}$ & $\boldsymbol{P}$ \\
\hline PT (liana vs. tree) & 1,39 & 0.10 & 0.75 \\
\hline TT (control vs. removal) & 1,39 & 46.5 & $<0.0001$ \\
\hline Season & 1,38 & 31.3 & $<0.0001$ \\
\hline Species & 2,38 & 834.3 & $<0.0001$ \\
\hline PT $\times$ TT & 1,39 & 9.26 & 0.002 \\
\hline PT $\times$ season & 1,38 & 0.16 & 0.92 \\
\hline TT $\times$ season & 1,38 & 4.98 & 0.03 \\
\hline PT $\times$ species & 2,38 & 1.54 & 0.46 \\
\hline TT $\times$ species & 2,38 & 41.6 & $<0.0001$ \\
\hline Season $\times$ species & 2,36 & 130.3 & $<0.0001$ \\
\hline PT $\times$ TT $\times$ season & 1,38 & 0.17 & 0.92 \\
\hline PT $\times$ TT $\times$ species & 2,38 & 5.35 & 0.07 \\
\hline PT $\times$ season $\times$ species & 2,36 & 6.03 & 0.20 \\
\hline TT $\times$ season $\times$ species & 2,36 & 8.41 & 0.08 \\
\hline PT $\times$ TT $\times$ season $\times$ species & 2,36 & 1.24 & 0.87 \\
\hline
\end{tabular}

This mixed effects model also took into account spatial variation associated with the blocked design (site), autocorrelation associated with taking measurements on multiple seedlings within a single plot (plot), taking measurements on the plots over time (census), and autocorrelation of measurements taken on the same individuals over time (random effect in the statistical model = census/site/plot/seedling ID). We used the pbkrtest package in $R$ to estimate denominator degrees of freedom $(d f)$ and report here on $d f$.small. In the mixed effects model framework, denominator degrees of freedom differ depending on the metric described 


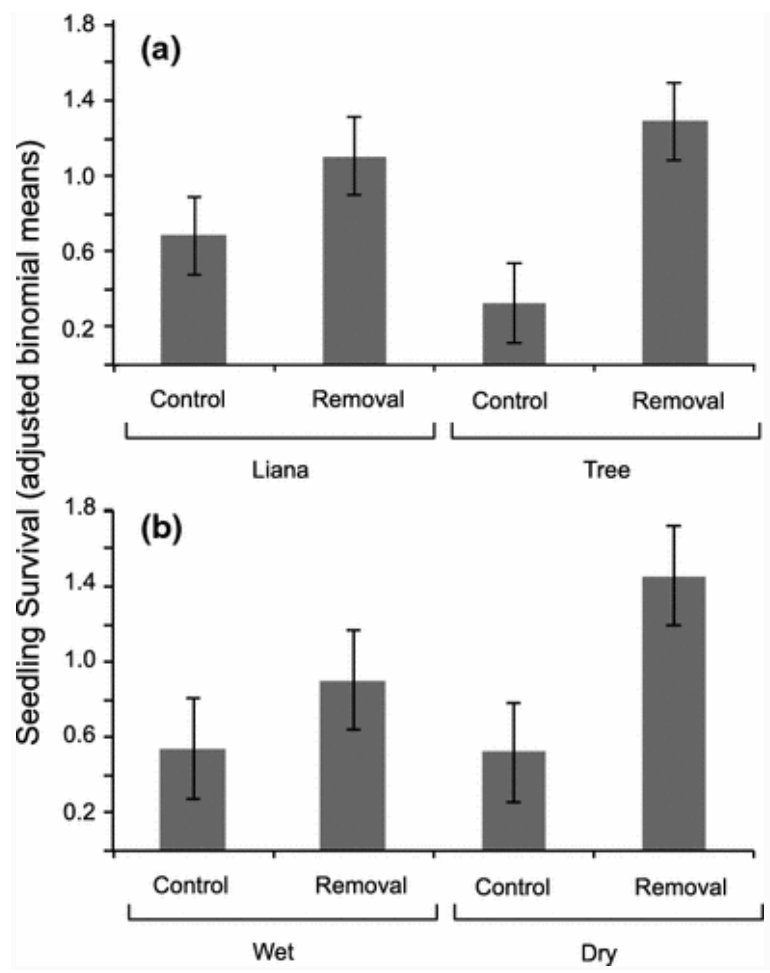

Fig. 2 Tree seedling survival (adjusted means) following liana and tree removals, a over the entire 3-year period and $\mathbf{b}$ comparing wet season and dry season survival on Gigante Peninsula, Panama. Values are adjusted means $\pm \mathrm{SE}(n=1,440)$ determined in the four-way ANOVA framework adjusted for multiple comparisons among

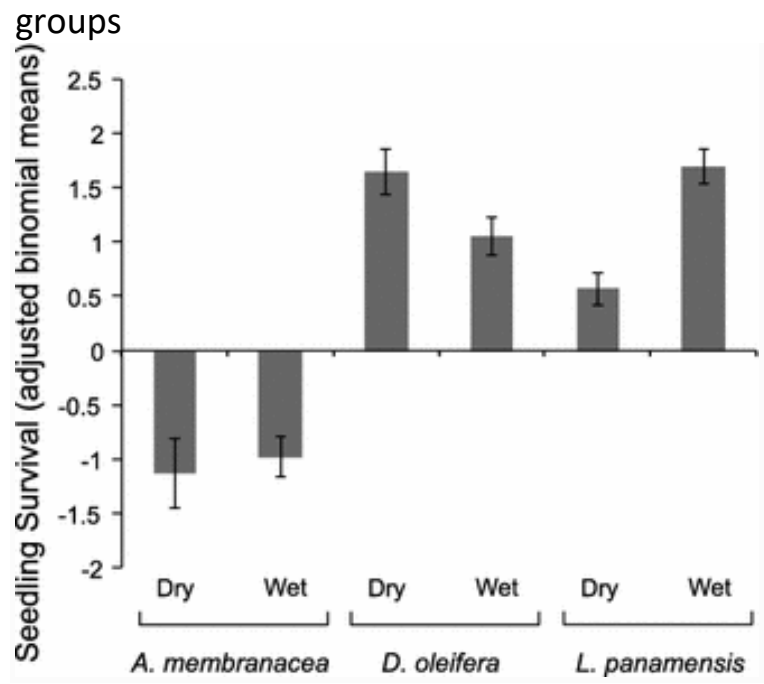

Fig. 3 Tree seedling survival (adjusted means) of three tree species during the wet and dry seasons in a tropical forest in central Panama. Values are adjusted means \pm SE $(n=1,440)$ determined in the four-way ANOVA framework adjusted for multiple comparisons among groups

\section{Planted seedling growth}

Mean seedling growth averaged across all species was suppressed by both lianas and trees (Table $\underline{3}$ ). However, lianas and trees had different effects on the growth of different species during different seasons (site $\times$ treatment $\times$ season $\times$ species; Table $\underline{3}$ ). Specifically, D. oleiferagrowth was strongly and uniquely suppressed by liana competition but not tree competition during the dry season (Fig. 4 a). During the wet season, $D$. oleifera growth was also limited by lianas, but trees had a more negative effect on growth: $D$. 
oleifera grew $\sim 50 \%$ less in tree control plots than in liana control plots (Fig. $\underline{4 b}$ ). Conversely, both $L$. panamensis and $A$. membranaceae grew similarly across treatments in both the wet season and the dry season.

Table 3 Results of ANOVA examining the effects of site type (ST), treatment type (TT), species ID, and season on seedling relative growth rate (RGR, g seedling ${ }^{-1}$ day $^{-1}$ ) on the Gigante Peninsula, Panama. Degrees of freedom vary based on random effects as in Table 2

\begin{tabular}{|l|l|l|l|}
\hline Fixed effect & $\boldsymbol{d} \boldsymbol{f}$ & $\boldsymbol{F}$ & $\boldsymbol{P}$ \\
\hline ST & 1,55 & 0.002 & 0.96 \\
\hline TT & 1,55 & 16.0 & 0.0001 \\
\hline Season & 1,9 & 7.19 & 0.03 \\
\hline Species & 2,67 & 8.02 & 0.0007 \\
\hline ST $\times$ TT & 1,62 & 0.0006 & 0.94 \\
\hline ST $\times$ season & 1,55 & 1.19 & 0.28 \\
\hline TT $\times$ season & 1,55 & 0.33 & 0.57 \\
\hline ST $\times$ species & 2,62 & 0.02 & 0.99 \\
\hline TT $\times$ species & 2,62 & 11.1 & $<0.0001$ \\
\hline Season $\times$ species & 2,67 & 37.0 & $<0.0001$ \\
\hline ST $\times$ TT $\times$ season & 1,62 & 0.88 & 0.35 \\
\hline ST $\times$ TT $\times$ species & 2,67 & 0.06 & 0.95 \\
\hline ST $\times$ season $\times$ species & 2,62 & 2.29 & 0.11 \\
\hline TT $\times$ season $\times$ species & 2,62 & 3.78 & 0.03 \\
\hline ST $\times$ TT $\times$ season $\times$ species & 2,67 & 3.12 & 0.05 \\
\hline
\end{tabular}

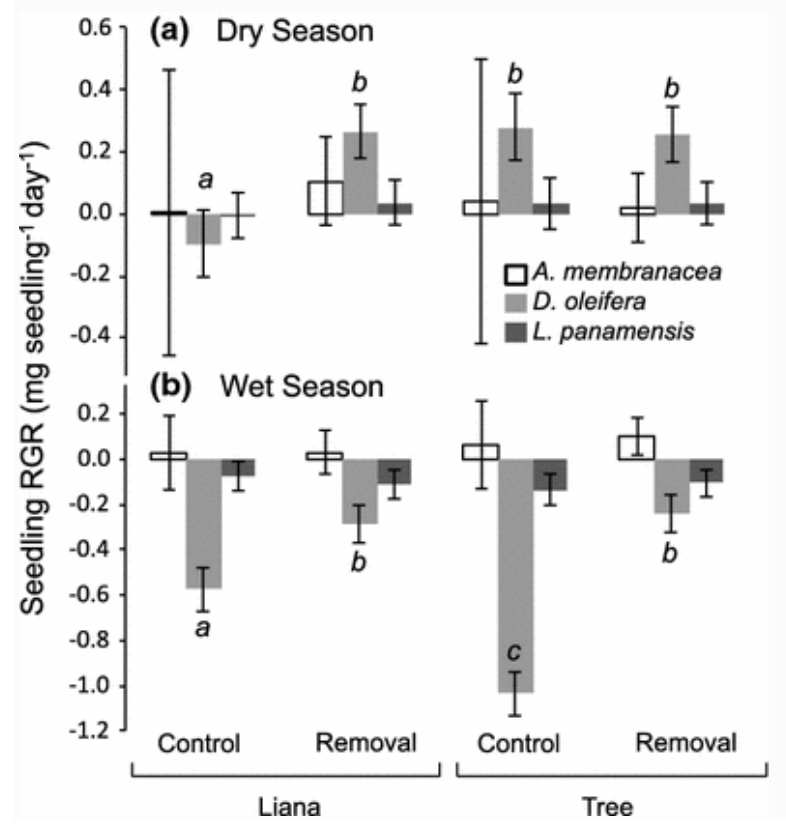

Fig. 4 Seedling relative growth rates (RGR) in liana and tree removal and control plots during adry and b wet seasons on Gigante Peninsula, Panama. Bars represent adjusted means \pm SE $(n=1,440)$. Letters indicate significant differences within species in response to site differences and treatment differences (statistical differences using post hoc Student's ttests) 


\section{Canopy openness}

Both liana and tree removals increased canopy openness and thus light in the forest understory directly above the seedling plots $\left(F_{1,87}=33.3, P<0.0001 ; \mathrm{Fig}\right.$. $\left.\underline{5} \mathrm{a}\right)$. Removing trees resulted in a greater increase in canopy openness than removing lianas (interaction term, $F_{1,87}=9.54, P=0.003$ ). Canopy openness was not related to standing stem growth across treatment types $\left(F_{1,639}=1.67, P=0.20\right)$. However, increased canopy openness in the understory was correlated with higher seedling survival $\left(F_{1,2324}=16.2, P=0.0001\right)$, particularly for $A$. membranaceaseedlings (interactions term, $F_{2,2324}=3.77, P=0.02$; Fig. $\underline{5} \mathrm{~b}$ ) and increased seedling growth (with no interaction with species, $F_{1,1326}=7.95, P=0.005$; Fig. $\underline{5} \mathrm{c}$ ).

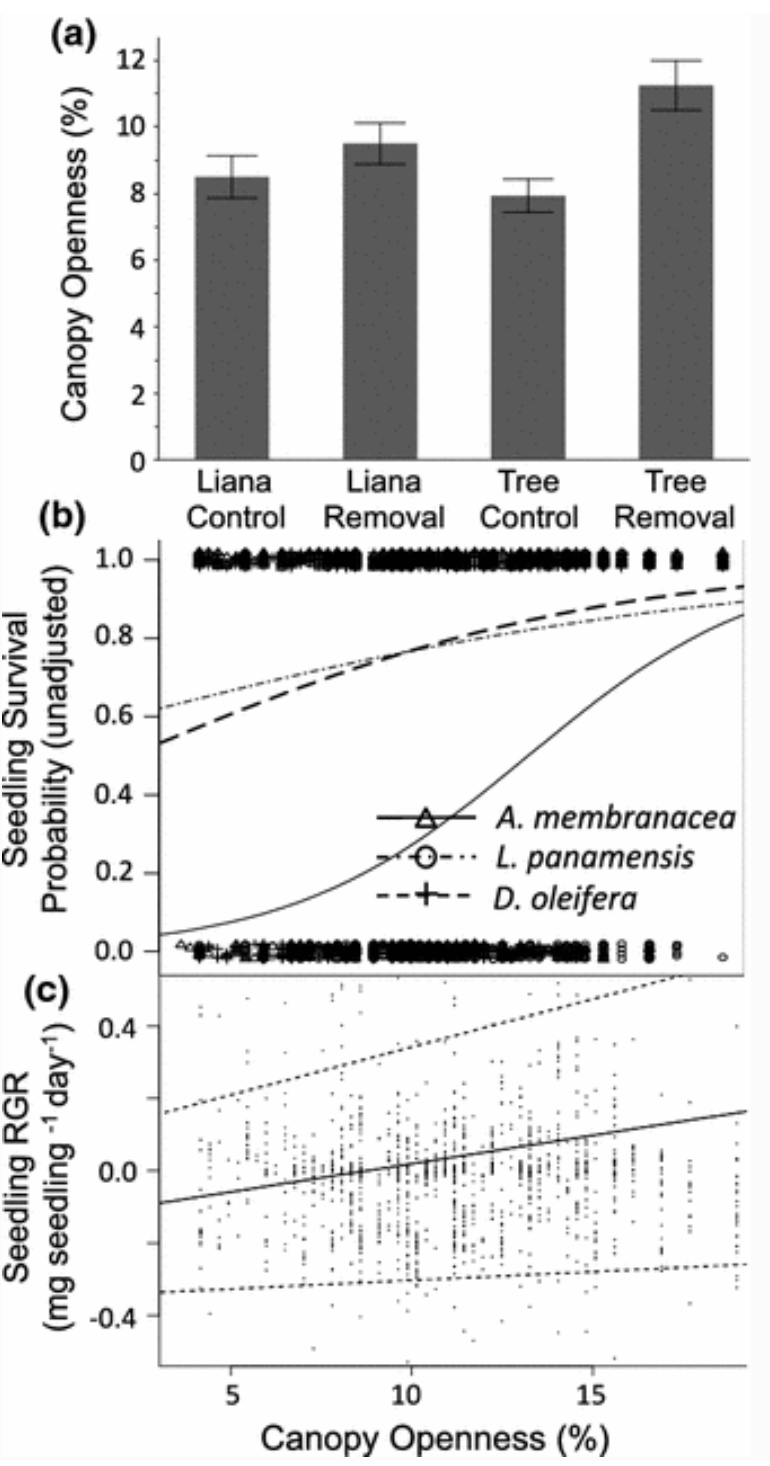

Fig. 5 a Variation in canopy openness among treatments. Relationship between canopy openness, $\mathbf{b}$ seedling survival, and c relative growth rate (RGR). We measured canopy openness directly above the seedling subplots using a spherical densiometer. Barsrepresent adjusted means ( $\pm \mathrm{SE} ; n=1,440$ ) and dotted lines in (c) represence $95 \%$ confidence intervals around the mean

\section{Discussion}

While previous work has demonstrated that the removal of lianas in a tropical forest can have markedly positive effects on remaining seedlings and saplings (Pérez-Salicrup 2001; Grauel and Putz 2004), this previous work 
focused on the general effects of biomass removals without accounting for the expected effects that would occur following the removal of any competitor biomass. To truly understand the competitive effects of either lianas or trees, we must assess competition in the context of a true experimental control. We report here on the first evidence of the unique effects that lianas have on understory plant growth and survival by controlling for the amount of biomass removed. Interestingly, whereas past work has demonstrated that the effects of lianas on trees in the canopy and in gaps are profoundly negative (e.g., Grauel and Putz 2004; Schnitzer and Carson 2010; Tobin et al. 2012; Schnitzer et al. 2014), using our procedural control approach we show that the unique effects of lianas in the understory are more diffuse and nuanced. Specifically, lianas and trees in the understory may affect each other in similar ways, with little differences in the results we found for the effects of lianas versus trees on uncut stems (Fig. 1). Furthermore, trees in the understory may have a stronger local impact on understory seedlings than lianas of similar biomass, where trees reduce the amount of light directly below their crown, which may lead to lower overall growth and survival of seedlings growing in dense tree patches. While past work has focused on the uniquely negative effects of lianas in tropical forests (e.g., Tobin et al. 2012), the results we report here indicate that the unique effects on understory plant growth and survival may not be as strong as previously considered.

Lianas can grow long distances laterally away from their rooting points (Putz and Windsor 1987), and even small diameter lianas ( $\sim 2 \mathrm{~cm}$ diameter) are commonly found growing in the forest canopy (Kurzel et al. 2006), where they spread into neighboring trees (Putz and Windsor 1987; Schnitzer and Bongers 2002). When in the canopy, lianas deploy a large amount of leaves over a broad area at the top of the forest canopy (Schnitzer and Bongers 2002). Ongoing experimental studies that removed lianas from large forest plots $(80 \times 80 \mathrm{~m})$ on Gigante Peninsula in Panama found that lianas constitute around $20 \%$ of the forest leaf area, and thus they significantly decrease light penetration into the understory at this scale (Rodriguez and Schnitzer, unpublished data). However, because the canopy of lianas is often spread over much larger distances than that of trees, the effects of lianas on light are also spread over larger distances, and their effect at a local scale (surrounding a focal tree) in the forest understory, such as in our study, may be small (Fig. $\underline{5} a$ ).

Conversely, trees may have a greater per capita effect than lianas on understory light levels in their immediate neighborhood. We found that canopy openness below trees was $1.4 \times$ higher after sapling removals than in unmanipulated controls, whereas canopy openness in liana removals was only about $1.1 \times$ higher than in unmanipulated controls (Fig. ). The architecture of a tree results in a confined crown that is typically positioned directly over the roots and attenuates the majority of light directly underneath itself. Trees tend to grow straight up from their rooting point (presumably due to their need to support their own weight) and even the crown diameter of large canopy trees are rarely more than 10x their basal diameter (Asner et al. 2002). For seedlings and understory plants growing near tropical trees, this shading may result in significant competition for light (and potentially other resources). Indeed, seedling survival (particularly for shade intolerant $A$. membranacea) in our study followed the same pattern as canopy openness (a proxy for light availability). Seedling survival increased most in plots where trees were removed compared to unmanipulated plots (Fig. 2a). Because light is particularly important to small germinating seedlings, the presence of trees in the understory is likely to reduce seedling survival more than the presence of lianas.

Similar to patterns observed in other systems (Wright et al. 2014) the relative impact of lianas versus trees may shift depending on the size and vertical positioning of neighbors. Lianas may compete most intensely with multiple canopy trees (Tobin et al. 2012) and in treefall gaps (Schnitzer and Carson 2000, 2010; Dalling et al. 2012; Ledo and Schnitzer 2014; Schnitzer et al. 2014). Trees and lianas may compete similarly with mediumsized (>0.5 cm DBH) understory plants (Fig. 1). At the seedling stage, the competitive relationship may reverse, where on average trees may have more intense competitive impacts on understory seedlings located near their 
rooting point than do lianas of similar biomass (Fig. 2a). Thus, the strength of liana and tree competition on trees may vary with the life-history stage of the target tree.

Lianas and trees may also have unique effects on tree seedling regeneration depending on the season and seedling species identity. Specifically, $D$. oleifera seedlings growing near lianas during the dry season grew significantly less than $D$. oleifera seedlings growing in liana removals or in any of the tree plots (removals or controls). Past work has suggested that lianas compete intensely for belowground resources during the dry season (Schnitzer 2005; Schnitzer et al. 2005; Dewalt et al. 2009), possibly due to well-developed root systems that can draw down soil water resources even when soil water is scarce (Andrade et al. 2005). In our study, $D$. oleifera was the only species that maintained higher survival rates during the dry season than during the wet season (Fig. 3). Consequently, D. oleifera was the only drought-tolerant seedling in our study (Tyree 2003), and the only species that was competing with neighboring lianas for similar belowground resources during the dry season. During the wet season, however, $D$. oleifera seedlings were most limited by competition from trees (Fig. $\underline{4 b}$ ). The release from competition of $D$. oleifera seedlings growing near trees during the wet season likely reflects a shift to competition for aboveground resources, where surrounding trees have a more negative effect on canopy openness above understory seedlings (Fig. $\underline{5}$ a).

Importantly, liana competition belowground may be even stronger than demonstrated in the current study. Lianas can grow adventitious roots along their stems and also grow long distances belowground (Restom and Nepstad 2004). The liana manipulation may not have completely removed liana competition belowground, as some lianas may have been rooted just outside the plot and may have continued to compete within the plot for belowground resources. Future studies may need to excavate or trench around plots to ensure equal manipulations of root competition between lianas and other growth forms.

Collectively, our findings indicate that lianas and trees compete differently with neighboring plants in the forest understory. Trees may have stronger local effects on a wider range of seedlings in the forest understory during the wet season, when competition for light may be more critical. In contrast, lianas may have stronger speciesspecific effects on tree seedlings in the understory during the dry season, when competition may be predominantly belowground. Finally, the growth-form-specific and species-specific interactions we show here may be important for long-term forest dynamics. We demonstrate that interactions with seedlings may be different in liana-dominated versus tree-dominated patches in the understory. Consequently, the observed increase in liana density, biomass, and productivity at the expense of trees in neotropical forests (Schnitzer and Bongers 2011; Schnitzer et al. 2014) may further impact long-term forest community composition via altered seedling dynamics.

\section{References}

Andrade JL, Meinzer FC, Goldstein G, Schnitzer SA (2005) Water uptake and transport in lianas and co-occurring trees of a seasonally dry tropical forest. Trees 19:282-289. doi: 10.1007/s00468-004-0388-X

Asner GP, Palace M, Keller M et al (2002) Estimating canopy structure in an Amazon forest from laser range finder and IKONOS satellite observations. Biotropica 34:483-492

Brown S (1997) Estimating biomass and biomass change of tropical forests: a primer. Food and Agriculture Organization of the United Nations, Rome

Dalling JW, Schnitzer SA, Baldeck C et al (2012) Resource-based habitat associations in a neotropical liana community. J Ecol 100:1174-1182. doi: 10.1111/j.1365-2745.2012.01989.x

Dewalt SJ, Schnitzer SA, Chave J et al (2009) Annual rainfall and seasonality predict pan-tropical patterns of liana density and basal area. Biotropica 42:309-317. doi: 10.1111/j.1744-7429.2009.00589.x

Englund SR, O'Brien JJ, Clark DB (2000) Evaluation of digital and film hemispherical photography and spherical densiometry for measuring forest light environments. Can J For Res 30:1999-2005 
Gentry AH (1991) The distribution and evolution of climbing plants. In: Putz FE, Mooney HA (eds) The biology of vines. Cambridge University Press, Cambridge, pp 3-50

Gerwing J, Schnitzer S, Burnham R et al (2006) A standard protocol for liana censuses. J Biol Conserv 38:256-261

Grauel WT, Putz FE (2004) Effects of lianas on growth and regeneration of Prioria copaifera in Darien, Panama.

For Ecol Manag 190:99-108. doi: 10.1016/j.foreco.2003.10.009

Kurzel BP, Schnitzer SA, Carson WP (2006) Predicting liana crown location from stem diameter in three

Panamanian lowland forests. Biotropica 38:262-266. doi: 10.1111/j.1744-7429.2006.00135.x

Ladwig LM, Meiners SJ (2009) Impacts of temperate lianas on tree growth in young deciduous forests. For Ecol Manag 259:195-200. doi: 10.1016/i.foreco.2009.10.012

Ledo A, Schnitzer SA (2014) Disturbance and clonal reproduction determine liana distribution and maintain liana diversity in a tropical forest. Ecology. doi: 10.1890/13-1775.1

Myers JA, Kitajima K (2007) Carbohydrate storage enhances seedling shade and stress tolerance in a neotropical forest. J Ecol 95:383-395. doi: 10.1111/j.1365-2745.2006.01207.x

Pérez-Salicrup D (2001) Effect of liana cutting on tree regeneration in a liana forest in Amazonian Bolivia. Ecology 82:389-396

Phillips OL, Vásquez Martínez R, Arroyo L et al (2002) Increasing dominance of large lianas in Amazonian forests. Nature 418:770-774. doi: 10.1038/nature00926

Poorter H, Lewis C (1986) Testing differences in relative growth rate: a method avoiding curve fitting and pairing. Physiol Plant 67:223-226

Putz F (1983) Treefall pits and mounds, buried seeds, and the importance of soil disturbance to pioneer trees on Barro Colorado Island, Panama. Ecology 64:1069-1074

Putz F, Windsor D (1987) Liana phenology on Barro Colorado Island, Panama. Biotropica 19:334-341

Restom TG, Nepstad DC (2004) Seedling growth dynamics of a deeply rooting liana in a secondary forest in eastern Amazonia. For Ecol Manag 190:109-118. doi: 10.1016/j.foreco.2003.10.010

Schnitzer S (2005) A mechanistic explanation for global patterns of liana abundance and distribution. Am Nat 166:262-276

Schnitzer S, Bongers F (2002) The ecology of lianas and their role in forests. Trends Ecol Evol 17:223-230

Schnitzer SA, Bongers F (2011) Increasing liana abundance and biomass in tropical forests: emerging patterns and putative mechanisms. Ecol Lett 14:397-406. doi: 10.1111/j.1461-0248.2011.01590.x

Schnitzer S, Carson W (2000) Have we forgotten the forest because of the trees? Trends Ecol Evol 15:375-376

Schnitzer SA, Carson WP (2010) Lianas suppress tree regeneration and diversity in treefall gaps. Ecol Lett 13:849-857. doi: 10.1111/j.1461-0248.2010.01480.x

Schnitzer S, Kuzee M, Bongers F (2005) Disentangling above-and below-ground competition between lianas and trees in a tropical forest. Ecology 93:1115-1125

Schnitzer S, DeWalt S, Chave J (2006) Censusing and measuring lianas: a quantitative comparison of the common methods. Biotropica 38:581-591

Schnitzer S, Rutishauser S, Aguilar S (2008) Supplemental protocol for liana censuses. For Ecol Manag 255(3):1044-1049

Schnitzer SA, Mangan SA, Dalling JW et al (2012) Liana abundance, diversity, and distribution on Barro Colorado Island, Panama. PLoS ONE 7:e52114. doi: 10.1371/journal.pone.0052114.s001

Schnitzer SA, van der Heijden G, Mascaro J (2014) Lianas in gaps reduce carbon accumulation in a tropical forest. Ecology. doi: 10.1890/13-1718.1

Tobin MF, Wright AJ, Mangan SA, Schnitzer SA (2012) Lianas have a greater competitive effect than trees of similar biomass on tropical canopy trees. Ecosphere. doi: 10.1890/ES11-00322.1

Toledo-Aceves T (2014) Significance of remnant cloud forest fragments as reservoirs of tree and epiphytic bromeliad diversity. Trop Conserv Sci 7:230-243 
Toledo-Aceves T, Swaine MD (2008) Above- and below-ground competition between the liana Acacia kamerunensis and tree seedlings in contrasting light environments. Plant Ecol 196:233-244. doi: $10.1007 / \mathrm{s} 11258-007-9347-0$

Tyree MT (2003) Desiccation tolerance of five tropical seedlings in Panama. relationship to a field assessment of drought performance. Plant Physiol 132:1439-1447. doi: 10.1104/pp.102.018937

Tyree MT, Velez V, Dalling JW (1998) Growth dynamics of root and shoot hydraulic conductance in seedlings of five neotropical tree species: scaling to show possible adaptation to differing light regimes. Oecologia 114:293-298

Windsor DM (1990) Climate and moisture variability in a tropical forest: long-term records from Barro Colorado Island. Smithsonian Institution Press, Washington, DC

Wright JS (2001) Plant diversity in tropical forests: a review of mechanisms of species coexistence. Oecologia 130:1-14. doi: $10.1007 / \mathrm{s} 004420100809$

Wright $S$ (2005) Tropical forests in a changing environment. Trends Ecol Evol 20:553-560

Wright AJ, Schnitzer SA, Reich PB (2014) Living close to your neighbors - the importance of both competition and facilitation in plant communities. Ecology. doi: 10.1890/13-1855.1 